\title{
Artigo
}

Dossiê: Tempo de pausa ou de crise?

\section{"É preciso incluir os bebês!" Sentidos e apostas no diálogo com mulheres-mães}

"¡Los bebés deben estar incluidos!" Direcciones y apuestas en el diálogo con mujeres-madres

"Babies must be included!" Directions and bets in the dialogue with womenmothers

\author{
Nazareth Salutto \\ Universidade Federal Fluminense, Brasil
}

Recebido em: 08/09/2020

Aceito em: 22/12/2020

\section{Resumo}

O artigo apresenta reflexões iniciais de pesquisa que discute a categoria conceitual bebês na área da Educação. O recorte emerge da leitura de entrevistas semiestruturadas realizadas com um grupo de mulheres-mães e indaga: o que suas narrativas permitem compreender sobre olhares e concepções sobre ser bebê? Escutar mulheres-mães mobiliza a circularidade de sentidos e apostas que apontam a necessidade da sociedade, de modo mais estrutural, assumir a prerrogativa de que é preciso incluir os bebês (Ploennes, 2014). Gottlieb (2012), Scavone (2001; 2004), Rezende (2015), referendam a tessitura do trabalho.

Palavras-chave: Bebês e Mulheres-mães. Sociedade. Pesquisa.

\section{Resumen}

El artículo presenta reflexiones iniciales sobre la investigación que discute la categoría conceptual de bebés en el área de Educación. El corte surge de la lectura de entrevistas semiestructuradas realizadas a un grupo de mujeres-madres y se pregunta: ¿Qué permiten entender sus narrativas sobre miradas, concepciones sobre ser bebé? Escuchar a las mujeres-madres moviliza la circularidad de significados y apuestas que apuntan a la necesidad de que la sociedad, de manera más estructural, asuma la 
prerrogativa de que es necesario incluir a los bebés (Ploennes, 2014). Gottlieb (2012), Scavone (2001; 2004), Rezende (2015), avalan el tejido del trabajo.

Palabras clave: Bebés y Madre mujer. Sociedad. Investigación.

\begin{abstract}
The article presents initial reflections of research which discusses the conceptual category of babies in the area of Education. The cut emerges from the reading of semi-structured interviews carried out with a group of women-mothers and asks: what do their narratives allow to understand about looks, conceptions about being a baby? Listening to womenmothers mobilizes the circularity of meanings and bets that point to the need for society, in a more structural way, to assume the prerogative that it is necessary to include babies (Ploennes, 2014). Gottlieb (2012), Scavone (2001; 2004), Rezende (2015), endorse the fabric of the work.
\end{abstract}

Keywords: Babies and Mother women. Society. Research.

Dedicado a Esther Noro (in memoriam).

Deveria eu começar, de forma mais convencional, com as histórias das mães desses bebês [...]? (Gottlieb, 2012, pp. 37)

\title{
Palavras iniciais
}

Pode-se afirmar que a presença dos bebês torna possível tanto a reinvenção quanto a continuidade das sociedades. O conjunto de sentidos que envolve a chegada dos bebês no mundo são definidos por pactos estabelecidos no interior das culturas, reunindo ritos e práticas que os precedem, contornam suas histórias desde o seu nascimento, forjam compreensões que fundam gestos, escolhas, olhares endereçados a essas novas pessoas que chegam cotidianamente ao mundo.

Quais dimensões dos contextos que acolhem e circundam os bebês nos seus inícios são conhecidas e tomadas como parte da construção da própria tessitura social? Para Ploennes (2014, s.p., grifos próprios), a sociedade brasileira ainda não incluiu o bebê como prioridade no seu debate estrutural, de modo que "as suas necessidades e os seus direitos se resumem hoje ao espaço do privado, à casa e ao meio familiar". Em que medida conhecer histórias que precedem a imersão dos bebês nos contextos sociais mais amplos, pode potencializar a construção de uma agenda político-social que envolva diferentes áreas (Saúde, Educação, Políticas Sociais, Comunicação, Antropologia, Sociologia, Psicanálise, entre outras) incluindo-os como legítimos possuidores de direitos na estrutura social?

Salutto, N. "É preciso incluir os bebês!" Sentidos e apostas no diálogo com mulheres-mães 2 
Essas e outras questões impulsionam as reflexões deste artigo, que se desdobra de projeto de pesquisa' institucional situado na área da Educação Infantil, tendo como um dos seus objetivos entrecruzar olhares de diferentes atores sociais (famílias, professoras, professores, gestores públicos, dentre outras/os) no que diz respeito às suas concepções sobre os bebês. O recorte aqui proposto apresenta narrativas de um grupo de mulheresmães que participaram do movimento inicial da investigação, como veremos adiante.

A Constituição Federal (Brasil, 1988, s.p., grifos próprios), no seu artigo 205, institui que a "educação, direito de todos e dever do Estado e da família, será promovida e incentivada com a colaboração da sociedade, visando ao pleno desenvolvimento da pessoa, seu preparo para o exercício da cidadania e sua qualificação para o trabalho". Posteriormente, a Lei de Diretrizes e Bases da Educação Nacional (Brasil, 1996) define a Educação Infantil como a primeira etapa da educação básica, estabelecendo o atendimento educacional de crianças até $5 \operatorname{anos}^{2}$ de idade em creches e pré-escolas, ficando a cargo dos municípios a elaboração de critérios para essa inserção. Em linhas gerais, o atendimento público e gratuito tornou possível o ingresso para todas as crianças com meses de vida em instituições educacionais ${ }^{3}$. Tal processo envolve amplo e complexo histórico, que não propomos aprofundar neste artigo, que permite reconhecer os desafios colocados à Educação na emergência de constituir estratégias e princípios que orientem um trabalho que coteje o pleno desenvolvimento da pessoa (Brasil, 1988).

Mas, que pessoa é essa que pode viver sua inserção na Educação Infantil quando não anda nem fala, que, no contexto dessa etapa educacional, vive e experimenta transformações que resultam das relações interpessoais, intersubjetivas e do complexo e exigente exercício de inserção na cultura? Essa indagação parece pertinente, uma vez que tensiona considerar singularidades. Não há dúvidas de que uma criança de colo, que vive processos iniciais de construção da linguagem, da autonomia dos próprios movimentos corporais, entre outros aspectos, revela travessias do constituir-se ser humano da cultura (Pino, 2005) diferentes das crianças que falam, andam, correm, pulam e se comunicam verbalmente. O que se tem aprendido a observar do miúdo, dos detalhes sutis dessa travessia, no contexto da Educação Infantil? Além de observar, como se tem compreendido e sustentado as sutilezas desse percurso humano?

No que tange aos estudos com/sobre bebês no contexto da Educação Infantil, revisão de literatura de documentos e pesquisas da área da Educação Infantil (Barbosa \&

\footnotetext{
1 Trata-se da pesquisa, em fase inicial, intitulada "Olhares e narrativas de mulheres, mães, famílias, professoras e professores sobre concepções e imagens sobre ser bebê", coordenada pelo Grupo de Estudos e Pesquisa em Educação, Infância, Bebês e Crianças/GERAR, da Universidade Federal Fluminense.

2 Alteração estabelecida a partir da Lei no 11.274 (Brasil, 2006), que dispõe sobre a duração de 9 (nove) anos para o ensino fundamental, com matrícula obrigatória a partir dos 6 (seis) anos de idade.

3 Esse tipo de atendimento já ocorria em creches privadas. Contudo, diante da prerrogativa legal, torna-se direito de todas as crianças.
}

3 - Linhas Críticas, Brasília, DF, v. 26 (2020) - Ahead of print, p. 3-20 
Richter, 2010; entre outros) revela a recorrência de uso dos termos bebês, crianças bem pequenas, sem que, muitas das vezes, esteja evidenciada a justificativa para tal definição. O que, então, definiria o termo na sua dimensão teórico-conceitual? Corte etário, eleição de modos singulares de manifestações e expressões (os balbucios, o engatinhar, a dependência de um outro que provenha a manutenção de necessidades básicas como higiene e cuidados corporais), seu lugar no debate social e político?

Singularidades dos modos de se manifestar e expressar daqueles que têm sido denominados pelo termo bebês vêm ganhando expressividade no cenário da investigação científica, sobretudo na Educação Infantil (Guimarães, 2008; Coutinho, 2010; Mattos, 2018; Arruda, 2019)4. Tal movimento permite reconhecer a constituição de pelo menos dois movimentos que se articulam: a perspectiva de se assumir os bebês como categoria teórico-conceitual de investigação; redimensionamento dos sentidos e propostas no contexto da formação e das práticas de professoras e professores que trabalham com essas pessoas.

Arruda (2019) assume investigar metodologicamente a categoria bebê a partir de três eixos: condição, situação e lugar. A partir de levantamento de pesquisa, a autora constata a precariedade da oferta de atendimento para aqueles cuja idade é inferior a um ano de vida, levando-a a justificar o uso do termo bebê como sujeito de investigação a partir do déficit do atendimento em creches na Baixada Fluminense. Desse modo, o corte etário não delimita o ser bebê, mas situa-se na ausência do cumprimento político, sem que com isso se pretenda instituir uma delimitação conceitual para o bebê, por compreender que a "condição do "bebê" enquanto sujeito está além de uma idade específica, e que os limites etários servem para designá-lo a uma pertença temporal bastante precisa que configura uma imagem complementar à sua existência, a partir do olhar do outro, construída dentro de modelos socialmente sancionados" (Arruda, 2019, p. 20).

Perspectivas que, longe de serem neutras, impõem desafios epistemológicos, éticos, metodológicos e levam a indagar: quais são as implicações, desafios, limites, possibilidades de se assumir o termo bebê como categoria teórico conceitual de estudo e investigação? De que modo reconhecer e legitimar especificidades, sobretudo transicionais dos modos de ser, de se expressar, sem provocar ruptura epistêmica com o conceito de criança? De que modo a sociedade tem se debruçado sobre a complexidade das travessias experimentadas pelas crianças, desde que são bebês? Se não há contornos que sustentem a legitimidade de um termo, o que revela sua polissemia no cenário das pesquisas?

Para Nascimento et al. (2020, p. 440):

${ }^{4}$ Também contribuem na construção deste debate Delgado e Nörnberg (2013).

Salutto, N. "É preciso incluir os bebês!" Sentidos e apostas no diálogo com mulheres-mães 4 
Olhar o bebê a partir do que the é peculiar impacta nas práticas, nas pesquisas, nas políticas. Do mesmo modo que é incontornável o olhar que temos hoje para a(s) infância(s) e para a(s) criança(s), que nos alerta sobre nossa responsabilidade e ações, almejamos que nos próximos anos o bebê seja também um debate central na sociedade, nos responsabilizando em conceber um mundo que respeite e favoreça suas interações e modos de construir conhecimentos e constituir-se como pessoa.

Coadunando com a necessária vigilância epistêmica que o debate exige, faz-se necessário destacar que, na referida pesquisa que origina o presente artigo, a perspectiva adotada para debater sobre ser bebê reflete a intenção de mapear e compreender modos de ser e existir implicados nos processos iniciais da vida, de modo que este recorte se delimita mais em tatear indícios sobre concepções do que definir um com corte etário para a categoria bebê. $O$ intuito de compreender modos de ser bebê se propõe como aposta que tencione o reconhecimento social da delicadeza implicada no constituir-se pessoa da/na cultura, nas travessias ordinárias que fundam lugares de pertencimento das pessoas na sociedade. Bebês, portanto, são aqui reconhecidos e tomados como pessoas de relação, cujas expressões, manifestações, singularidades são reconhecidas como intensos processos interpessoais, intersubjetivos de inserção e imersão na cultura que os acolhe. Como pessoas que ocupam esse lugar no mundo, refletem e refratam sentidos e apostas da sociedade na qual estão inseridos e, desse modo, revelam muito do que a sociedade manifesta de si mesma.

Como se entrecruzam olhares de duas significativas instituições responsáveis pelo acolhimento, provisão, sustento, amparo nos primeiros anos de vida: famílias e instituições de Educação Infantile É na articulação dessas apostas que escutar mulheresmães revela sua face mais potente. Tal nuance favorece entrecruzar o debate sobre os bebês na interface com os estudos feministas, suas agendas de lutas, tensões, conquistas que reposicionam mulheres-mães e, no seu escopo, os próprios bebês. No campo da Educação Infantil, o que podemos aprender sobre os bebês escutando as histórias das mulheres? No que tange a um cenário mais amplo das ciências humanas e sociais, os estudos remetem às condições do ser mulher, nas transformações dos sentidos da maternidade, da paternidade, das reconfigurações em torno das perspectivas de família e de gênero (Scavone, 2004; Finco et al., 2018). O recorte proposto neste artigo emerge de entrevistas semiestruturadas realizadas com mulheres-mães, com o intuito de alargar o debate em torno de concepções sobre ser bebê, para além da fronteira educacional, incluindo outra esfera do discurso social.

Na tensão entre denúncia e intensa agenda de luta das/dos trabalhadoras/res, o bebê emerge como alguém que altera a paisagem social, cidadão de direitos, filha/o da mulher e mãe trabalhadora que reivindica do Estado e da sociedade amplo debate de fala e de escuta para os inúmeros desafios implicados no papel de receber uma nova pessoa que chega ao mundo, num cenário de transformações políticas e sociais que alteram as dinâmicas em torno da divisão sexual do trabalho. Nesse sentido, a 
consolidação da creche 5 como direito das crianças, desde que são bebês, a um espaço potencial de sociabilidade, convivência com e entre pares e outros adultos, contribuiu no reordenamento do debate, uma vez que "o movimento feminista trouxe para a luta a crítica ao papel tradicional da mulher na família e a defesa da responsabilidade de toda a sociedade em relação à educação das novas gerações' (Finco et al., 2015, p. 9) e, também, por ratificar que "a desvalorização do bebê decorre de ideologias de gênero e de idade que valorizam o padrão adulto e masculino associado à produção e à administração da riqueza e não à produção e à administração da vida" (Rosemberg, 2015, p. 212).

Escutar mulheres-mães diz respeito a fomentar certa circularidade das narrativas (Rezende, 2015) que envolvem os bebês antes dos ritos de iniciação e inserção na vida cultural mais estendida, nas instituições ${ }^{6}$, tornando visíveis e públicos os desafios que atravessam a decisão (ou não) de se ter um bebê, pois, "ao narrarem suas gestações, as mulheres falam de si para outros através de histórias que articulam suas biografias pessoais a mudanças nas relações sociais" (Rezende, 2015, pp. 215-216), políticas, culturais. Por que escutar essas histórias? Porque narrar e escutar histórias permite aos sujeitos encontrar $O$ fio de suas tradições, conhecer seu passado, suas origens, reconhecendo-se como parte integrante da comunidade a qual pertence, da qual participa, uma vez que a "[...] minha própria história é construída e partilhada por elementos que estão presentes na memória de outra pessoa [...]. Cada história individual está inevitavelmente enredada em várias histórias, formando a dimensão coletiva de cada existência pessoal" (Jobim e Souza \& Pereira, 1998, p. 40).

Escutar histórias sobre a chegada dos bebês permite mapear sensibilidades, escolhas, receios, laços humanos que adentram e penetram o universo da cultura, das instituições, da vida pública nas quais os bebês e aqueles responsáveis pelos seus cuidados pertencem. Partilhar histórias sobre os começos reafirma o necessário compromisso com a solidariedade humana, no reconhecimento dos desafios que envolvem responsabilidade social, política, pública no acolhimento e legitimidade dos bebês como integrantes da humanidade, confirmando sua continuidade.

\section{Histórias de escolhas e começos}

Estamos as três sentadas na frente dela. Pouco a pouco vamos sentindo o calor do fogo, tão próximo, uma sensação agradável de torpor nos invade, o fogo é apenas uma luz leve. Está na hora de contar histórias... (Mukasonga, 2017, p. 118)

Em A mulher dos pés descalços, Scholastique Mukasonga (2017) desvela às/aos leitoras/res diferentes cosmovisões sobre maternidade, educação e cuidado das

\footnotetext{
5 Sobre o histórico da creche no Brasil, entre outras referências, ver: Rosemberg (1989), Haddad (1991) e Kramer (2003).

6 Por estar situada no campo da Educação Infantil, compreende-se a creche como potencial espaço de inserção dos bebês no universo coletivo, para além da sua família nuclear.
}

Salutto, N. "É preciso incluir os bebês!" Sentidos e apostas no diálogo com mulheres-mães 6 
crianças, desde que são bebês, na cultura tutsi7. Sustentada por memórias construídas junto à mãe e outros membros de sua família, escreve sobre o lugar reservado às mulheres que se tornam mães, o papel da comunidade na participação da nova função que emerge a partir de uma nova chegada ao mundo. Nasce um bebê e os sentidos partilhados entre os sujeitos da comunidade também são alterados.

Em outra cultura, a dos Beng 8 , antes de nascer, os bebês habitam outro mundo, junto aos seus ancestrais; uma temporalidade plena de experiências e sabedoria. Por esse motivo, são recebidos e cuidados com máximo respeito quando chegam a este mundo, referendando a relação dos adultos em relação a este grupo:

[...] durante minhas viagens anteriores ao campo para Bengland, eu tinha ignorado a existência da amizade entre as gerações, assim como o respeito que as pessoas idosas têm pelas crianças. Graças a Nathaniel [seu filho], eu comecei a notar regularmente esses padrões na sociedade Beng antes invisíveis para mim. Foi quando observamos quanta atenção os adultos do nosso núcleo residencial dispensavam a Nathaniel. Inicialmente deduzi que isso se devia aos status de nosso filho como uma criança de pais privilegiados [...]. Mas, logo comecei a notar que muitos adultos tratavam suas próprias crianças, assim como as crianças de outras pessoas, de todas as idades, com um nível de respeito que eu não tinha notado. Perguntavam com calma a opinião das crianças, enquanto aparentemente lhes davam ordens [...] (Gottlieb, 2012, p. 47 - grifos próprios)

A cultura Beng revela padrão social que inclui a participação de bebês e crianças na construção coletiva da vida, permitindo compreender que, naquele contexto, pessoas de pouca idade são levadas a sério (Ingold, 2019). Norte americana, na construção de sua etnografia a pesquisadora traça paralelos entre a sociedade Beng e seu país nativo. Entre outros aspectos, os modos de gestar e parir das mulheres Beng, bem como o papel da comunidade são destaques constantes, que influenciaram sua própria experiência no tornar-se mãe:

Desde o início, minha primeira gravidez e parto foram estruturados decisivamente pelo que eu tinha observado nas vilas Beng. Sem romantizar nossos anfitriōes Beng, sem ignorar as extraordinárias dificuldades de sua pobreza opressiva, eu continuo a sentir que tinha muito a aprender com muitas de suas práticas e premissas intelectuais por detrás delas. Tendo observado um regime de reprodução delineado por contornos radicalmente diferentes daqueles que me rodeavam nos Estados Unidos, foi fácil enxergar as práticas de gravidez e parto de meus conterrâneos, tão peculiares na melhor das hipóteses e, em alguns casos, preocupantes. (Gottlieb, 2012, p. 40)

A imersão numa cultura radicalmente oposta à sua sensibiliza a pesquisadora a assumir o estranhamento frente a lógicas ocidentais e europeias que influenciam, até hoje, práticas e concepções. De que modo semelhanças e singularidades se apresentam no interior de nossas próprias estruturas?

Tendo essa indagação como disparador e horizonte, sem pretender esgotá-la, passamos agora ao contexto da pesquisa. Optou-se por apresentar um desenho geral do contexto e um breve perfil das mulheres-mães entrevistadas, por meio do qual expõem seus

\footnotetext{
7 Povo remanescente de Ruanda, na África Central.

8 Povo nômade, dos menores grupos étnicos dos aproximadamente sessenta grupos que ocupam a nação da Côte d'Ivoire, no oeste da África.
}

7 - Linhas Críticas, Brasília, DF, v. 26 (2020) - Ahead of print, p. 7-20 
caminhos no processo de tonar-se mãe para, em seguida, refletir sobre suas apostas nas concepções sobre ser bebê.

Diferentes autoras (Scavone, 2004; Moura \& Araújo 2004; Priori, 2018; 2020), destacam sobre o processo histórico da transformação dos sentidos em torno da maternidade, sobretudo, nos últimos quarenta anos, salientando sobre:

[...] a maternidade como fenômeno social marcado pelas desigualdades sociais, raciais/étnicas, e pela questão de gênero que the é subjacente. Consequentemente, as mudanças e implicações sociais da realização dessa experiência não atingem da mesma forma todas as mulheres, países e culturas, apesar de existir um modelo de maternidade preponderante nas sociedades ocidentais contemporâneas, em que sobressaem características gerais de proles reduzidas e mães que trabalham fora. Portanto, é necessário considerar neste debate a inserção das mulheres no mercado de trabalho, sua presença no mundo público e os impactos que estes fatos trouxeram à instituição familiar e, em decorrência, à experiência da maternidade [...] (Scavone, 2004, p. 172)

As narrativas das mulheres-mães partilhadas neste texto evidenciam essas questões, e permitem compreender que discutir concepções sobre ser bebê envolve camadas complexas do processo histórico que entrecruzam micro e macro. Em seus relatos, as mulheres-mães falam sobre escolhas, gravidez, parto, nascimento, maternidade e paternidade, casamento, vida, trabalho, solidão, expectativas, desejos, o papel do acesso à informação, decisões sobre institucionalização dos bebês, condições de vida, impacto da chegada do (s) bebê (s) nas suas vidas, suas impressões sobre a pessoa que o bebê é. Para esse grupo, marcado por diversidade econômica, geográfica, de formação, o olhar para o bebê como pessoa destaca-se como força de seus relatos.

Entre março de 2019 e maio de 2020', foram entrevistadas oito mulheres, com idades entre 28 e 41 anos, grávidas e mães de bebês até doze meses, de classe média de metrópole brasileira. O contato com as entrevistadas se deu a partir da rede de conhecimentos e relações do grupo de pesquisa. Os encontros ocorreram em diferentes bairros e espaços (residência das pesquisadoras e das entrevistadas; espaços públicos como livrarias, shopping, universidade, entre outros). A proposta da pesquisa foi sempre bem acolhida por todas, que mostravam interesse e abertura na partilha de suas experiências. No final de cada encontro, foram consultadas sobre o desejo de manterem seus nomes em sigilo. Com exceção de uma participante (incluindo seu companheiro), todas optaram por manter seus nomes próprios, bem como de seus filhos e filhas, conforme indicado entre parênteses.

A metodologia adotada foi entrevista semiestruturada (questões fechadas e um conjunto de perguntas abertas). À época da entrevista, duas mulheres viviam a primeira gestação; quatro mães da/o primeira/o filha/o; uma, mãe de duas (uma bebê de doze meses e uma adolescente de dezesseis); uma, mãe de três (uma menina de treze e, dois meninos, de dez anos e doze meses). Todas vivem uniões (casadas/união estável) heterossexuais e a decisão pela gravidez envolveu os respectivos companheiros. Todas exerciam atividade profissional antes da gravidez e, com exceção de uma,

\footnotetext{
9 As entrevistas continuam sendo realizadas de modo remoto devido à Pandemia do novo Coronavírus.
}

Salutto, N. "É preciso incluir os bebês!" Sentidos e apostas no diálogo com mulheres-mães 8 
retornaram/retornariam após o período de licença maternidade. A renda média/casal é entre três e mais de dez salários mínimos. Todas possuem nível superior (áreas da Educação e/ou Psicologia, Música, Jornalismo), assim distribuídos: doutorado concluído (3); mestrado concluído (1); mestrado em andamento (3); especialização (1). Necessário destacar que, embora com formações iniciais em áreas distintas, todas as entrevistadas trabalham e/ou participam de atividades na área da Educação' ${ }^{10}$.

Optou-se por apresentar as mulheres e seus relatos e, em seguida, retomar destaques de suas narrativas. Esse encaminhamento metodológico coaduna com a perspectiva de colocar em primeiro plano histórias dos começos. O que cada história pode revelar em torno de concepções sobre ser bebê?

Tinha tomado uma decisão sobre a maternidade na minha vida: eu seria mãe. Essa decisão era inegociável. Eu entendi que na vida a gente vai negociando várias coisas. Coisas que a gente sonha e a gente vê que aquele sonho não vai ser um sonho realizado de vida, e você constrói novos sonhos... A gente se reinventa, se ressignifica a todo momento. Isso [ser mãe] para mim era inegociável e ninguém me tiraria isso. Eu tinha tomado uma decisão na minha vida de que a maternidade não estava em negociação no meu conjunto de sonhos... E a adoção foi um tema para mim, porque eu estava solteira. [...] E aí eu conheci o Allan, que também é adotivo e sempre falou em adotar. Falei: 'pronto!' Estamos resolvidos. Quando a gente se casou, eu mais velha, a gente logo um ano, ou menos, depois de ter casado, a gente começou a tentar. Parei de tomar remédio e eu não conseguia engravidar. Não conseguia, não conseguia [...]. Descobri que eu tenho um problema, uma espécie de menopausa precoce. E esse diagnóstico foi muito terrível. Às vezes a gente ouve histórias de outras pessoas, fica consternada pela experiência do outro, mas quando passa por você, passa pelo seu corpo... Foi uma experiência muito triste, por muitos motivos, mas foi muito forte no sentido desse corpo feminino que é inútil. Foi muito terrível isso para a minha vida. Enfim, e aí é no contato com esse médico, ele orientou que a gente fizesse imediatamente um tratamento. A gente procurou um tratamento, que não existe na rede pública, que é caríssimo. Mais uma vez, a gente fica pensando nessa questão de como não dá para não pensar nessas questões fora da discussão de classe. Eu só pude fazer isso porque eu pertenço a uma classe privilegiada, e eu pude pagar por isso, com dificuldades, parcelado, não importa. Mas eu pude. [...]. Quando eu fui para o hospital cheia de expectativas do que ia acontecer, logo que eu saí do procedimento vem a notícia do médico de que não tinha dado certo. Voltamos muito tristes, muito arrasados, e aí eles começaram a indicar para gente um outro tratamento que chama ovodoação ${ }^{11}$. [...] esse tratamento é muito caro, e quando a gente fala desse tema de reprodução humana e tal, no Brasil tudo é muito confuso, porque a gente não tem legislação, a gente não tem no sistema público, então de novo quem tem dinheiro é que consegue fazer, porque é um tratamento que está em torno de sessenta mil reais numa clínica. A gente não dispunha desse dinheiro, a gente tomou a decisão de se inscrever numa Universidade de São Paulo [...]. A gente ficou nessa. Diante das dificuldades a gente retomou o projeto da adoção. Rapidamente começamos a nos movimentar para descobrir como é o processo. No Brasil você tem que fazer um curso [...]. A gente começou a preparar a documentação. No Natal, faltava uma certidão para a gente tirar, que por conta do recesso da justiça, só poderia ser feito em janeiro, e aí eu descobri que estava grávida nesse intervalo. Quando eu já tinha decidido, já estava tudo encaminhado para a adoção, veio a notícia da gravidez. Estou falando um pouco do processo da gravidez, de escolher. Foi uma escolha. Mas ao mesmo tempo foi uma surpresa, né? De um corpo doente, sem óvulos, eu fiquei grávida. (Marina, 37 anos, mãe do Gabriel)

\footnotetext{
10 Há outros grupo de mulheres sendo entrevistadas após este período, cujos dados não foram analisados neste artigo.

11 "Ovodoação - Ovodoação - é a técnica de RA no qual o gameta feminino é fornecido por uma mulher distinta da que receberá este". (Santos, 2009, p. 5).
}

9 - Linhas Críticas, Brasília, DF, v. 26 (2020) - Ahead of print, p. 9-20 
Estava sentindo meu corpo estranho, mas a minha mente que já estava também um pouco ansiosa com questão da gravidez... [nesse período, não havia planejado definitivamente engravidar] Mas, eu comecei a me sentir mal. Aí, eu falei: 'vou fazer um teste'. Tinha um mês.... O teste de farmácia deu positivo. Aí eu fiquei muito ansiosa, contei para todas as pessoas. Liguei paro Vitor [seu companheiro], comemoramos. Já estava me sentindo a grávida! Ah! Já estava entrando na fila preferencial do avião. Isso foi por volta, de vinte e oito, vinte nove de outubro (2018) mais ou menos. Eu fui para o ensaio do Maracatu e tive uma hemorragia, uma grande hemorragia. Eu já tinha entrado em contato com uma médica, tinha feito os exames, não tinha nem pego os resultados dos exames ainda. E aí eu fiquei muito desesperada assim. Na época também eu estava com outro convênio, que não me dava muita assistência. Não tinha, por exemplo, a assistência de uma maternidade perto, de emergência. Não tinha nenhum conhecimento. E aí, fiquei muito desesperada com aquela hemorragia e fui para uma consulta particular na Perinatal12. Lá fiz vários exames e descobri que não estava mais grávida, ou, talvez não tinha nem implantado [o embrião]. Foi muito difícil. A gente ficou muito triste, eu fiquei muito triste, sabe? Com a expectativa, com a coisa de dizer para as pessoas que estavam me dando os parabéns que eu não estava mais grávida. Fiquei muito, muito triste. Eu lembro dessa noite, eu não dormia. O resultado chegou de madrugada e eu não dormi. Fiquei pirando com todos os julgamentos do mundo, e com as minhas questões. Mais aí o Vitor virou para mim assim e falou assim: "ah, amor! Eu gostei muito. Agora eu quero ser pai. Agora vamos tentar valendo!" E aí a gente tentou valendo e eu nem menstruei mais. Essa foi contada como a minha última menstruação, essa hemorragia. E aí no mês seguinte eu realmente estava grávida. Lembro [...] que eu achava que ainda estava passando mal dos efeitos daquele processo [da hemorragia], um dia, realmente eu não consegui chegar numa aula na UFF, e falei: 'vou fazer outro teste'. Aí eu fiz o teste e deu gravidíssima! (Soraia, 33 anos, mãe da Dora)

A ideia de ser mãe foi construída há muito tempo. Não foi uma coisa que veio quando eu engravidei. Eu sempre quis, isso era uma coisa que eu sempre quis. E, ao mesmo tempo, eu sempre imaginei que esse momento era um momento que ia demandar da gente muitas coisas, e eu nunca quis dividir esse momento com outras coisas. Uma coisa era certa, o desejo de ter. Tinha certeza que eu queria ser mãe; mas o desejo de engravidar, foi sendo construído, amadurecido. A gente sempre dizia: 'será que a gente é muito egoísta?' Porque a gente gostava da nossa vida a dois, e ficava pensando de ter um filho e as coisas mudarem, mas não foi uma decisão 'vai ser agora!'. É um processo que vai acontecendo, você vai se dando conta, quando você vê, já está envolvido, você fala com mais naturalidade. De repente, a gente já se viu indo ao obstetra, fazendo exames. Depois do obstetra, a gente ficava: 'vamos liberar esse mês, vamos liberar o outro....' ainda muito calcados na vida que a gente tinha, pensando na vida que a gente tinha. [...]. O que era da nossa responsabilidade a gente foi fazendo. Procuramos uma médica, cuidamos da saúde, organizamos nossa vida para que a gente tivesse ter total disponibilidade de tempo. Eu tinha a certeza de que eu não queria dividir esse momento com nenhuma outra coisa, nenhum outro projeto grande [...]. Então, eu pensava: depois que eu terminar o doutorado, estiver mais tranquila, a gente vai pensar nisso. Eu acho que o que a gente tinha mais preocupações, e talvez isso seja o que mais trouxe um certo medo para o Lucca [seu companheiro]. A primeira lição que a gente tirou, desde que eu engravidei é de que a chegada de um bebê é a quebra total de previsibilidade. De repente, a gente não tem mais controle disso. Isso era uma coisa que assustava a gente, porque têm coisas que não vão depender da gente, que não acontecem como a gente deseja. Então, teve uma primeira questão, que foi a primeira lição assim de ter engravidado, essa imprevisibilidade da vida; e a outra coisa, é que o Teo ainda não nasceu, e a gente não se vê mais sem ele [...]. Eu acho que estava num processo de gestação interior, mesmo antes de estar grávida. Veio a coragem para a gente falar: 'não, agora a gente vai liberar!' E aí, desde o dia em que eu fiz o exame, e descobri que eu estava grávida, não demorou a cair a ficha, foi muito rápido e eu pensei: 'estou grávida!' (Maria Antônia, 36 anos, mãe do Teo)

Foi um planejamento nosso. Sou casada há onze anos. Eu sou paraibana. Eu venho de uma família de cinco irmãos. Eu via aquela questão, as meninas muito jovens, treze, quatorze anos, doze... Casavam e tinham filhos. E via aquela criança sendo criada sem previsão. Aquilo me incomodava, mesmo sendo muito jovem. Aquele contexto que se apresentava, eu falava: 'ah, não quero isso'. E aí com dezessete anos eu vim, mas vim com a ideia de que eu não queria ter filhos. E aí foi passando o tempo, casamos, e eu achava que não era o momento, que não estávamos preparados. A nossa

12 Rede médico hospitalar especializada em obstetrícia.

Salutto, N. "É preciso incluir os bebês!" Sentidos e apostas no diálogo com mulheres-mães 10 
situação também, acho que psicológica, financeira. Mas, de uns três anos para cá, essa questão vem amadurecendo, essa vontade. Começamos a sentir falta de algo, nossa vida estava mais estruturada. Começamos a planejar, pensar nessa criança de modo planejado, fui ao médico. Mas, sempre quando chegava na hora, 'ah! Vamos esperar mais um pouquinho'. E, realmente, o que foi decisivo, eu já trabalho com educação infantil, foi estar com os bebês bem pequenos o ano passado. Então, quando engravidei, eu estava com eles. E eu acho que o contato com eles, posso te dizer, me deu mais segurança. Quando eu tive contato com esses seres potentes que são os bebês, com aquela interação, com aquela vivência, eu acho que eu me decidi [...]. Foi decisivo. Eu chegava encantada aqui em casa falando dos bebês. Que potência que tem um bebê! [...] Agora, o dia em que realmente descobri, mesmo sendo algo que eu queria, foi uma sensação muito estranha. Porque eu acredito que vem uma carga muito grande. A sociedade traz um peso muito grande para a mulher, para o homem também. 'Ah! Como é que vai ser a minha vida agora? Como é que eu vou trabalhar?' Eu estou fazendo o processo do mestrado. Veio tudo! E aí, acho que depois dos três meses foi transbordando. Comecei a sentir a minha barriga crescer. Primeiro dia que você sente mexer é emocionante, inexplicável. Eu acho que é a primeira vez você fala assim: 'ih, tem uma vida aqui dentro!' Porque, até então vai mudando, mas você não sente. Mas quando mexe, você tem a consciência. (Edilane, 35 anos, mãe do Gael)

Tenho uma filha de dezesseis anos e eu queria ter outro filho. É muito engraçado pensar nesses dois lados. Me pego ainda hoje olhando para a Helena, vendo como é, como eu sou a mãe da Helena e como eu era a mãe da Eduarda. Eu tinha dezenove anos quando engravidei da Eduarda. Já trabalhava no Município do Rio, mas não tinha uma série de vivências, de estudos sobre a criança. Elas são duas pessoas completamente diferentes. E eu me vejo pensando nas questões, como eu reajo a determinadas questões com a Helena e como eu reagia com a Eduarda. Acho que esse tempo todo me deu essa condição de poder refletir sobre coisas que antigamente eu achava [estranhas, perigosas] e, hoje em dia, penso: 'deixa pra lá, faz parte do processo!'. Apesar de ser muito diferente fisicamente, você ser mãe de um bebê com trinta e seis anos e você ser mãe de um bebê com dezenove. Uma disposição que não é mais a mesma. Mas, em muitos momentos, ficou mais leve, por conta de ter um outro olhar mesmo para as coisas que acontecem com a criança. A gravidez da Duda não foi planejada. Foi bem tumultuado, porque tive muitas questões com o pai dela, a gente se separou. A Duda ainda era muito pequena, voltei a morar com minha mãe. Tinha todo um outro processo de trabalho, a gente tinha uma licença maternidade menor no Município, uns sete meses no total, quatro de licença maternidade e três de amamentação. Agora a gente já tem um ano. Aí fui trabalhar com Eduarda bem menor. Sempre quis ter um outro filho, sempre quis que Eduarda tivesse um irmão. Como fiquei muitos anos separada, fui deixando, esperando. Quando casei com o Jorge, já tínhamos conversado sobre isso, que eu queria ser mãe novamente. No início ele não tinha muita pretensão de ter filho, e eu falei: 'olha, eu não quero ser mãe'. E a gente foi acordando. Mas, também haviam coisas. Estudar [...]. Muitos anos depois acabei entrando em Pedagogia, fiz à distância, pelo CEDERJ, para conciliar com todas as questões profissionais que eu tinha. E fomos esperando um pouco. O Jorge acabou fazendo Pedagogia também, junto comigo, para me incentivar. Foi a segunda graduação dele. E nesse meio tempo ficamos de ver o que a gente ia fazer. Acabou que eu tive uma trombose em 2015. Fiquei o ano de 2016 todo em tratamento, até conseguir realmente me livrar da trombose no final do ano. E, então, começou esse processo de ter um filho. A ginecologista vetou, a princípio, porque achava que eram muitos riscos, como não conseguir levar a gravidez até o fim. E aí fiquei um tanto quanto frustrada, pensando no que eu ia fazer da vida. Ao mesmo tempo, descobri que tenho uma mutação genética, que me faz ter propensão a ter trombose, e que eu não poderia mais fazer uso de nenhum contraceptivo hormonal. Ficamos nessa, pensando no que íamos fazer e, nesse meio tempo veio Helena. Quando a gente pensava o que ia fazer, Helena já resolveu e veio! (Michelle, 36 anos, mãe da Eduarda e da Helena)

Eu escolhi ser mãe, não foi por acaso. Eu e Davi, eu e o meu esposo. Eu já queria há muito tempo, mas eu esperei estar bem financeiramente. Nós dois queríamos. Eu queria mais do que ele, porque ele sempre achou que fosse muita responsabilidade, e ele não se sentia ainda seguro para tal responsabilidade. Aí eu fiz de tudo para que esse caminho fosse trilhado. Fiz um concurso público, entrei que era o que eu queria, ter uma estabilidade, ter um horário mais flexível para estar em casa, já que no outro trabalho eu não conseguia. Trabalhava numa escola particular. Chegava oito horas da noite em casa. Então eu ficava pensando muito nisso, não tinha como morar por lá, meu marido

11 - Linhas Críticas, Brasília, DF, v. 26 (2020) - Ahead of print, p. 11-20 
também trabalha no centro. Aí eu trilhei esse caminho, consegui. Entrei no serviço público e pensei: agora é a hora. É aí eu conversei com meu marido dizendo da minha vontade, que eu estava me sentindo segura para isso. E ele falou que tudo bem, ainda estava um pouco inseguro, mas que não tem jeito; essa hora chega, acho que a gente nunca fica completamente preparado. Essa sensação de plenamente preparado acho que isso não existe, né? A gente está sempre com algo a mais... Não, 'ainda tem isso... ainda falta aquilo'. Então, no caso, o que faltava para gente ali também era a casa. Estávamos pagando muito de aluguel... Enfim. Aí fui ao ginecologista: 'está tudo liberado, você está bem, você pode ser mãe, volte aqui grávida!' Aí ele se assustou um pouco [o companheiro], mas 'vamos lá! Estou animado também! Aí eu parei de tomar meu remédio, tomava pílula para evitar. Eu fiquei um bom tempo, uns seis meses por conta da pílula, eu fiquei evitando de uma outra maneira que fiquei com medo das reações da pílula. Até o médico pediu para esperar, enfim. Quando eu parei de evitar total, um mês depois eu estava grávida. Foi muito rápido, eu nem esperava, porque quando eu saí do ginecologista ele falou que eu estava liberada e tal, mas que eu tinha uma probabilidade de demorar um pouco a ter filho por conta de uma endometriose: 'geralmente, essas mulheres costumam demorar mais a engravidar'. Fiquei muito triste no momento, e foi aí que eu falei: 'então, já que eu vou demorar para engravidar, uma coisa que eu sempre quis, agora que eu posso, não vou ter. Já que eu vou demorar, eu vou esquecer isso. Vou deixar isso para lá e vou ver o que a vida me traz. E aí um mês depois eu estava grávida. Então eu acho que relaxei tanto, que eu fiquei grávida. Então, nós escolhemos. A minha gestação foi incrível, maravilhosa. Pude trabalhar. Gravei um cd grávida! Foi muito emocionante, porque ele estava ali comigo. Eu estava na trigésima sexta semana, ele já estava lá, chutando para valer. Quando eu cantava, ele não mexia, ficava quietinho. Mas, quando eu colocava o fone de ouvido para escutar, eu não cantava, e aí ele mexia muito, sem parar. Então, às vezes eu sentava lá para escutar, ficava lá sentada descansando, com a mão na barriga. A gente colocava o som alto, para todo mundo [equipe] escutar. Nossa! Como ele mexia, mas mexia demais, de todo mundo olhar: 'nossa a barriga está mexendo muito, muito!' Era incrível! (Thaís, 28 anos, mãe do Lucas)

Lara e o Nico não foram planejados, era um relacionamento ainda muito inicial. E eu fui me dando conta disso ao longo do tempo. Claro, claro que não funcionou, eu não conhecia direito o pai dos meus filhos. Assim que eu engravidei da Lara foi um choque muito grande. Eu tinha vinte sete anos, tinha morado fora e estava voltando para o Brasil. Tinha acabado de fazer uma formação, estava tentando me inserir no mercado de trabalho. Uma profissional autônoma, o que era muito difícil. Com uma abordagem de trabalho corporal que era uma coisa muito desconhecida, eu trabalho com a técnica de Alexanderis. E aí de repente eu engravido. E aí foi muito difícil. Compreender que eu estava grávida e compreender esse trajeto todo, me envolver nele, numa confusão de sentimento tremenda, uma gravidez muito emocionada, muito ambivalente de sentimentos e tal. E veio a Lara que é uma figura incrível, um bebê que eu fui me dando conta de que era um bebê tranquilo. Me surpreendeu profundamente em muitas coisas, porque a princípio eu não planejei [...]. E aí quando a Lara tinha um ano e três meses, eu engravidei do Nico. E aquela confusão toda de novo. 'Meu Deus! Outro bebê'. Estava complicado o casamento... Falei: 'vou encarar, vou encarar com alegria essa gestação, porque já sei como é que é. Não preciso me ocupar disso tanto como eu me ocupei, quanto me preocupei. Vou levar a vida, tocar a vida e o bebê vai nascer daqui a nove meses'. Só que foi uma gestação de risco. Foi uma gestação que eu tive uma placenta prévia, que é quando a placenta migra para baixo, ao invés dela se localizar no alto da barriga, ou nas laterais altas, ela foi escorregando, escorregando, escorregando e a placenta é um órgão da gestação [...]. A partir do quarto mês comecei a ter hemorragia. No sétimo mês estava completamente deitada dentro de casa. Fazendo repouso absoluto na gestação, não podia carregar a Lara, não podia alçar a Lara, não podia passear com a Lara. Então assim, foi uma gestação que me colocou em xeque completamente e nasceu o Nico nasceu no início do oitavo mês de gestação. Foi no tempo possível. E aí eu tive um choque hemorrágico no parto, eu fui para uma UTI ele foi para outra [...]. Eu cheguei em casa alguns dias depois, me dei conta depois do risco que tinha sido a gestação, que risco tinha sido o parto. Me dei conta disso na maternidade. Pensei: 'nossa, eu estou aqui, ele está aqui; deu tudo certo; está tudo bem com esse menino; tá tudo bem, não tem problema nenhum!'. E amanhã ele vai para o quarto ficar com você. Falei: 'nossa, está tudo ótimo!' Eu lembro que eu não dormi a noite inteira e no dia seguinte eu estava cheia de leite. A

13 "A Técnica Alexander tem como objetivo principal uma reeducação psicomotora, ensinando como corpo e mente podem funcionar juntos no desempenho de todas as atividades diárias [...]". (Técnica Alexander, s.d.)

Salutto, N. "É preciso incluir os bebês!" Sentidos e apostas no diálogo com mulheres-mães 12 
enfermeira falou: 'que isso, está cheia de leite!' E aí eu fui pra casa com esse bebê muito pequenininho, muito diferente do meu outro bebê. Eu tive que ensinar ele a mamar e a instrução que eu tive para ensinar meu filho a mamar era irritar ele; era tirar a roupinha dele toda, fazer ele ficar com frio, coçar a cabecinha dele para ele abocanhar meu peito com força, porque ele era muito pequenininho [...]. Era uma outra história, um outro bebê; um bebê prematuro, fruto de uma gestação muito amedrontada e aí foi um bebê. Fiquei muito angustiada. Foi muito difícil aprender sobre esse novo bebê... Eu me separei, o tempo passou [...]. A gente estava muito a fim de ter bebê juntos [com Guilherme, seu atual companheiro], embora achasse que ia ser uma empreitada muito grande ter o terceiro filho. Eu e o Gui somos muito comprometidos com a vida deles. Eu tinha muita vontade de ter um outro filho com outra experiência de companheiro. Acabei engravidando uma vez de supetão e foi uma gestação tubaria. Eu perdi uma trompa e tudo aquilo de novo: 'Gente, não é possível!' Uma coisa doida, perdi uma trompa, internação de emergência, transfusão de sangue, hemorragia interna, tudo de novo. Logo depois, entrei no mestrado e falei: ' acabou essa ideia para mim. Acabou!' Jogamos a toalha. Isso é risco de vida para mim, já foi risco de vida na gestação do Nico, agora uma gestação tubaria, tenho uma trompa só, tenho dois filhos que não quero que fiquem órfãos. Eles estão comigo, então, acabou'. $E$, então, eis que um ano e meio depois, engravido no meio do mestrado com uma trompa só, sem a gente ter muita expectativa. Então, foi muito desejado o Joaquim, mais não foi planejado também. Eu acho que o Joaquim chegou há um ano atrás exatamente ressignificando toda uma potência em mim, que foi a potência de eu conseguir terminar o mestrado, de ter conseguido um bebê, de eu conseguir reunir alguma experiência de maternidade, de docência com crianças pequenas, a partir de uma experiência com técnicas corporais que era uma coisa meio marginal, que trazia de muito tempo comigo. E que eu não conseguia transformar aquilo numa coisa compreensível. (Lívia, 41 anos, mãe da Lara, do Nico e do Joaquim)

Sempre quis ser mãe, mas deixei esse sonho na gaveta. Investi na minha carreira e independência financeira primeiro. Quando terminei o doutorado, por ajuda da análise [terapia], pelo relógio biológico avançando, e pelo desejo de aumentar a família, criamos coragem. Foi bem planejado. E, por sorte, deu certo. No segundo mês, o resultado deu positivo. Choramos muito de felicidade. E de medo! Preparamos tudo com muito amor. Costurei boa parte do enxoval. Organizamos a casa, fiz todos os exames. Cuidei da alimentação, fiz exercícios. Quis parto natural desde o início. Estudamos sobre parto e amamentação. Fizemos chá de bebê. Na verdade, vários! Diana foi muito celebrada e cercada de amor desde a barriga. Foi quase terapêutico responder as questões do questionário... Porque, para mim, a maternidade é um momento de muita alteridade... Objetivamente, mudou a rotina, subjetivamente, mudou as prioridades, o que vale a pena brigar (eu e o pai estamos muito cansados, mas muito unidos), os sonhos de futuro (de viagens românticas para 'mal vejo a hora de ensinar ela a plantar!'). A admiração pelas outras mães, mesmo as desconhecidas. Mudou meu jeito de ver o mundo, minha paciência se alargou. (Raquel 33 anos, mãe da Diana) ${ }^{14}$

Desejo, experiência, vida, vontade, insegurança, saúde, medo, encontros, separações, planejamento, construção, susto, alegria, realização. Cada mulher, um relato, um ponto de vista. Na sutileza singular das experiências, sentidos históricos se cruzam. Entre todos, um fio parece unir a trama da narrativa: um bebê chegou na vida dessas mulheres. Muitas são as faces que emergem das entrevistas, constituindo movimento que revela processo histórico das transformações que impulsiona novos engendramentos familiares, bem como o exercício da maternidade:

Com mais acesso à educação formal e à formação profissional, as mulheres vão, no decorrer do século XX, ocupar gradativamente o espaço público, ao mesmo tempo em que mantêm a responsabilidade na criação do(a)s filho(a)s. Neste contexto, ser ou não ser mãe passou a ter uma dimensão reflexiva, a ser uma decisão racional, influenciada por fatores relacionados às condições subjetivas, econômicas e sociais das mulheres e, também, do casal. (Scavone, 2004, p. 174)

\footnotetext{
${ }^{14}$ A entrevista em torno das questões abertas foi realizada de modo remoto. Por motivos técnicos, a gravação foi perdida. Ficamos com as respostas do questionário.
}

13 - Linhas Críticas, Brasília, DF, v. 26 (2020) - Ahead of print, p. 13-20 
Semelhanças e diferenças as aproximam, revelando percursos históricos, mas também subjetivo, que reposiciona mulheres-mães na sociedade, processos formativos (como conjunto de experiências que articulam conhecimentos e aprendizados ao longo da vida), conjunto de valores partilhados com membros de seus núcleos, sustentando decisões dimensionadas por escolhas reflexivas (Scavone, 2004). Entre o desejo inegociável, construído, planejado, inesperado - e a decisão, são muitos os percursos que levaram as entrevistadas ao encontro com os bebês.

\section{Sentidos e apostas sobre ser bebê}

Já no dia seguinte, Marie-Thérèse colocava o bebê nas costas e passava, orgulhosamente, de casa em casa, antes de ir para o campo. A partir daí, o bebê já podia sair de casa: ele tinha sido adotado pelo vilarejo. (Mukasonga,2017, p. 69)

Conforme vimos, as narrativas compartilhadas pelas mulheres situam o percurso implicado ao tornarem-se mães, envolvendo processos formativos (estudo, redes, informações), conjunto de valores, dimensão reflexiva. Neste último tópico, busca-se levantar apontamentos a partir das narrativas que apontam concepções sobre ser bebê.

Você não tem uma concepção de bebê na sociedade como um sujeito, como uma outra pessoa. E ele é realmente uma outra pessoa. Então, o normal é que você faça as coisas nele e por ele, sem ter muita consciência de que ele é alguém que tem que estar ali naquela relação. Então, acho uma coisa muito difícil no dia a dia. Acho que, para você mudar concepção é realmente muito difícil, mas que eu venho buscando. Olhar para a Helena de uma outra forma, de me relacionar com ela de uma outra forma e de construir essa concepção de bebê. E o que é ser bebê, também de uma outra forma. Eu acho que tenho crescido muito com isso com a Helena. (Michelle)

Qual é o olhar que a sociedade lança para os bebês? Os processos formativos de vida articulam contextos político-sociais que legitimam o reconhecimento legal das crianças (Brasil, 1988, 1990), o que não significa afirmar que há clareza e coerência nas práticas sociais que levem em conta suas singularidades, tampouco que bebês e crianças usufruam plenamente dos seus direitos. Nesse sentido, processos formativos de vida e dimensão reflexiva nem sempre estão acordados entre os membros de uma mesma sociedade.

O que mais me assusta é o respeito ao bebê. Porque eu tenho a garantia do respeito [ao bebê], mas eu não sei como vou fazer para garantir que as pessoas o respeitem. Quando eu vou visitar um bebê na maternidade, penso: 'não vou colocar perfume, vou lavar a mão antes; não vou ficar pegando o bebê, ele acabou de chegar [...]'. Fomos visitar um bebê na maternidade. E nossos amigos chegaram falando muito alto, acenderam a luz e o pai imediatamente autorizou. Eu fiz uma observação: "gente, não acende a luz, ele está dormindo, parece que não está gostando...". Ele [o bebê] colocou a mão no olho, no rosto quando a luz acendev; fez um movimento assim [imita o gesto feito pelo bebê de levar à mão ao rosto]. E aí todo mundo começou a dizer: 'tem que ir se acostumando!' Eu acho que isso se tornou o comum, o natural, e aí eu vejo bebês invisíveis quando eles nascem [...] Isso tenho medo!Eu fico pensando: por que ele tem que se adaptar a essa loucura desse mundo tão rápido? Ele acabou de chegar. Ele precisa de um tempo... Será que não dá para esperar, será que a gente não pode ter um certo cuidado? (Maria Antônia)

Salutto, N. "É preciso incluir os bebês!" Sentidos e apostas no diálogo com mulheres-mães 14 
O processo de assimilação de concepções e ações no interior da sociedade se faz de modo lento, gradual, na tensão entre tradição e perspectivas que emergem do debate estabelecido pelos sujeitos, pela e na (s) cultura (s). Como delineado nos tópicos anteriores, discutir maternidade na atualidade reflete tanto o passado, quanto lança luzes no presente e no futuro. Nesse sentido, é possível traçar um paralelo entre sentidos do tornar-se mulher-mãe e o modo como reflete nas representações e concepções do ser bebê. Na convergência entre muitas áreas e campos, em apostas teóricoconceituais, metodologias de pesquisas, entre muitos outros aspectos, torna-se possível assumir que o bebê é uma pessoa, um outro que está ali, na relação.

O Joaquim nasce comigo tendo essa grande construção discursiva de que bebê é sujeito, bebê é gente, é gente inteira de tamanho pequeno. E aí isso é muito desafiador... O que isso significa de verdade no dia-a-dia com um bebê? (Livia)

Reconhecer discursivamente a legitimidade desse lugar não exclui o desafio de operar para sua materialidade, revelando o desafio que tensiona a vida cotidiana em direção à consolidação dessa aposta: o que significa de verdade assumir o bebê como uma pessoa de relação? Que indícios se fazem presentes na fronteira entre conceber e agir na legitimidade desse lugar do bebê como pessoa? Quantas e quais ações são, em pequena ou larga medida, desrespeitosas? Quantas luzes são acessas diretamente nos olhos dos bebês, tornando-os invisíveis como um outro para quem o respeito é direito? As escolhas reflexivas de uma mulher, mãe, grávida sobre quais estratégias podem garantir o respeito ao seu filho, revelam a fragilidade desse lugar na esfera social. Maternidade e concepção sobre ser bebê se veem, portanto, diante do desafio de lutar por legitimação pública. E isso dá medo.

Ser bebê? Ser bebê deve ser difícil, porque são muitos aprendizados... Eu acho que é muita gente em volta... Não sei, olhando para ele, dando 'pitaco', falando, "indo" lá [referência à interferência na ação do bebê]. Eu, por exemplo, várias vezes fui lá: 'tá engasgado?', batendo nas costas. Coitado! Eu acho que ser bebê é uma descoberta, é viver para o novo. Ser bebê é ser humano, é ser uma pessoa. O bebê ele está sempre buscando a sua autonomia por conta própria [...]. O bebê tem vontade, tem desejos também, assim como nós. (Thaís)

O bebê somos nós. Ela é o bebê, mas também eu, às vezes até o pai. O puerpério é um recomeço. Começo para ela, retorno à nossa infância para nós. Isso em termos de lembranças, resgatar memórias, mas também em viver sentimentos de maneira muito intensa [...]. Em outro sentido, o bebê é pessoa. Eu olho para a Diana como uma pessoa. (Raquel)

Cuidar dele, dar banho... É super cansativo [o cotidiano], mais eu vivo isso de um jeito diferente. Por dois motivos. Estou tão grata com essa possibilidade de ser mãe do Gabriel, que eu acho que recoloco os problemas, não dou relevo para o cansaço que existe [...]. O Gabriel tem um choro diferente à noite, um desconforto [...]. É um choro difícil até de acalmar, e ele me abraça. E não tem sensação melhor do que tirar ele do berço, quando ele reconhece que sou eu, e ele me abraça. Fico muito preocupada de fazer um relato romântico, mas é o que estou vivendo mesmo. É a minha experiência. Acho que esse amor é muito intenso e é um amor que humaniza a gente. (Marina)

Na prática, assumir o bebê como pessoa implica responsabilidade diante da materialidade das ações subjacentes a tal concepção. São verbos que parecem

15 - Linhas Críticas, Brasília, DF, v. 26 (2020) - Ahead of print, p. 15-20 
responder o que na prática significa assumir o bebê como pessoa: receber, cuidar, banhar, alimentar, aprender vestígios e sinais, garantir tempo para os aprendizados dos processos, olhar, descobrir, estar aberto.

Amar como decorrência de afetos atravessados pela materialidade do verbo agir, desponta como horizonte dos sentidos e apostas em torno das concepções sobre ser bebê. Num contexto de hipervalorização da racionalidade, muitas vezes em detrimento dos afetos, do sentir, falar sobre amor que humaniza pode ser compreendido como pouco rigor científico. Mas, ao contrário, são apostas ancoradas em experiências de dar e cuidar da vida (Scavone, 2004) atravessadas pelos/nos corpos das mulheres. Como a sociedade acolhe tais perspectivas? O que oferece como horizonte de cumplicidade para as tarefas implicadas nos verbos? $\bigcirc$ que mulheres, mães, trabalhadoras, responsáveis pela chegada, provisão, educação dos bebês, almejam do mundo?

Eu desejo muito que o mundo dê condições para que ela utilize as habilidades dela, em prol da sua independência, em prol de lutar pelo que acredita. Então, eu acho, eu tenho muito essa percepção, de que eu quero oferecer o máximo de condições, para que ela possa oferecer isso para o mundo. E eu acho muito lindo, eu vejo que ela já é essa pessoa [...] (Soraia, 21.03.19)

Eu acho que é um mundo que eu busco todo dia, um mundo que eu acho que começa com pequenas coisas do cotidiano. Porque, às vezes, a gente começa a pensar no mundo como algo muito grande, mas eu vou pensar no cotidiano. Eu quero um mundo em que ele [o bebê] seja escutado sensivelmente, um mundo onde ele possa ter suas ideias, opiniões. Um mundo onde ele possa se colocar, um mundo onde ele respeite as pessoas. E esse mundo é feito de pequenas coisas, que eu busco construir a cada dia, quando escuto um choro, vou até lá e pergunto: 'o que que foi? Por que você está chorando? O que que aconteceu?' E, muitas vezes, é só um abraço. Eu acho que é o mundo que eu quero para o meu filho. É esse mundo que eu busco construir todos os dias, na minha vida, nos espaços que eu frequento, na creche, com os bebês. O que eu espero que ele seja para o mundo? Eu acho que vamos construir juntos. (Edilane. 18.04.19)

Ingold (2019, pp. 13-14), assume a perspectiva de uma antropologia que leve os outros a sério. Isso significa comprometer-se com o movimento de olhar o outro para além do que ele faz e diz e, "mais do que isso, devemos encarar o desafio que eles colocam às nossas concepções sobre como as coisas são, o tipo de mundo em que vivemos e como nos relacionamos com ele".

O tipo de mundo que as mulheres-mães deste recorte de pesquisa almejam parece ser aquele que leve a elas próprias, suas narrativas e seus bebês a sério. $\bigcirc$ que isso significaria em plano prático? Não caberia à sociedade, no seu plano macro, comprometer-se com o desafio de olhar, escutar e, mais do que isso, reconhecer que a cidadania dos bebês se vincula a uma perspectiva de atuação no mundo que se faz na ação do presente? Ações que envolvem o reconhecimento das necessidades básicas de um bebê recém-chegado, que passará longos anos sob proteção e cuidado, se não dos seus responsáveis primeiros, do próprio Estado ${ }^{15}$ ? Se as necessidades diárias tais como alimentação, banho, zelo pela manutenção da saúde, educação -

\footnotetext{
${ }_{15}$ Aqui podem ser incluídos casos de recém-nascidos retirados do convívio de suas mães logo após o nascimento, ou em meses subsequentes ao nascimento, como é o caso dos filhos de detentas. Para aprofundamento do tema, ver Azambuja (2013).
}

Salutto, N. "É preciso incluir os bebês!" Sentidos e apostas no diálogo com mulheres-mães 16 
compartilhada com o Estado -, lazer, todas as outras que possam ser citadas, estão a cargo dos responsáveis primeiros, como a sociedade apoia qualitativamente tais ações? Rosemberg (2015) salienta que "vivemos uma época que proclama a igualdade de direitos entre homens e mulheres, mas não gera condições para o trabalho de mães de bebês ou crianças".

Reconhecer a cidadania e os direitos dos bebês convoca a implicação com um sentimento de construção de sociedade que: (i) os reconhece como pessoas, cidadãs legítimas de direitos; (ii) se compromete com ações pequenas do cotidiano que tornem seu entorno mais propício e de qualidade de vida (como os espaços públicos em que mães, demais adultos e bebês usufruam como esfera de sociabilidade coletiva da vida); (iii) respeite sentidos subjetivos e objetivos dos seus responsáveis de referência para que possam sustentar escolhas respeitosas aos bebês.

\section{Provisórios acabamentos}

As mães de Gitagata se preocupavam, antes de mais nada, com a educação das crianças... (Mukasonga, 2017, p. 136)

O presente texto apresentou apontamentos de pesquisa, situada na área Educação Infantil, que têm por objetivo mapear olhares, sentidos, concepções sobre ser bebê na sociedade. Trata-se de trabalho cujo processo se vê radicalmente atravessado pelo cenário que se impôs com a Pandemia do novo coronavírus. Neste momento, o Brasil soma $\circ$ indecente número de mais de 180 mil mortes, dentre eles, contabiliza-se inúmeras gestantes e puérperas que perderam suas vidas para a doença. Seus bebês, assim desejamos, estão acolhidos em outros colos e entornos de afeto. Estarão?

O recorte proposto neste trabalho emerge de parte das análises de entrevistas semiestruturadas realizadas com mulheres-mães. As análises permitem considerar que assumir o bebê como pessoa resulta das lógicas e pactos assumidos no interior da sociedade, que envolve o reconhecimento da mulher, da possibilidade de acesso a informações que possibilitem que tomem decisões reflexivas (Scavone, 2001) no que tange a decisão de tornar-se mãe.

Gottlieb (2012, p. 67) afirma que "o trabalho de campo é, algumas vezes, estimulante, outras vezes, desconcertante e sempre uma combinação peculiar de cabeça e coração". Nos identificamos com essa perspectiva, uma vez que escutar as histórias dessas mulheres - e em alguma medida foi escutar tantas outras vozes - nos atravessou de muitos sentidos, sobretudo no reconhecimento subjetivamente construído, mas objetivamente percebido de que todos fomos bebês um dia. Escutar permitiu nos reconectar com um tempo longínquo, mas que habita o interior de cada pessoa. Voltando ao nosso campo, nos indagamos: que dimensões dessas narrativas adentram os espaços coletivos de educação quando lá os bebês iniciam seus processos de 
inserção? O que sabemos sobre os seus inícios? De que modo escutar as narrativas de mulheres, mães, famílias pode contribuir no redimensionamento de um dado projeto de educação, de sociedade?

O conjunto do material apresentado contribui no alargamento de algumas perspectivas, delineando que o reconhecimento do bebê como pessoa envolve camadas complexas no interior do debate social, resultando de processo histórico que envolve, entre outros aspectos, transformações do papel da mulher na sociedade e nas culturas. Recortes de classe, raça, econômicos atravessam a construção das representações e imagens sobre ser bebê. As narrativas salientam o bebê como uma pessoa de relação, digna de direitos, o que não necessariamente se faz presente nas práticas cotidianas, embora seja reconhecido na legislação. Também indicam o desafio que atravessa a relação cotidiana, na qual se faz necessário redimensionar o tempo, aprender os indícios construídos nas relações, abertura para que possa construir o mundo todos os dias. Incluir os bebês implica, em larga medida, tomar conhecimento de seus começos, mas também do fio invisível da vida que conecta pessoas, tempos, espaços, culturas.

Que os tempos duros deste momento que atravessa a humanidade, ratifique a urgência de novos pactos sociais, sobretudo pelo comprometimento diário de confirmação do que preconiza a Carta Magna de 1988, (Brasil, 1988) sem que a sua confirmação seja seletiva.

\section{Referências}

Arruda, G. R. da S. (2019). Quem são e onde estão os bebês: conceito, políticas e atendimento na Baixada Fluminense. [Dissertação de mestrado não publicada]. Universidade Federal Rural do Rio de Janeiro.

Azambuja,M. R. F de (2013). Os bebês filhos de mães que cumprem pena privativa de liberdade. Gênero \& Direito, 1 (2), 46-67. https://periodicos.ufpb.br/index.php/ged/article/view/16947/9647

Barbosa, M. C. S., \&Richter, S. R. S. (2010). Os bebês interrogam o currículo: as múltiplas linguagens na creche. Educação Santa Maria, 35 (1), 85-96. https://periodicos.ufsm.br/reveducacao/article/view/1605/900

Brasil. (1988). Constituição da República Federativa do Brasil. Congresso Nacional do Brasil. Assembleia Nacional Constituinte. http://www.planalto.gov.br/ccivil 03/constituicao/constituicao.htm

Brasil. (1990). Lei n. 8.069 de 13 de julho de 1990 (Dispõe sobre o Estatuto da Criança e do Adolescente). Presidência da República. Casa Civil. http://www.planalto.gov.br/ccivil_03/leis//8069.htm

Brasil. (1996). Lei 9.394 de 20 de dezembro de 1996 (Estabelece as diretrizes e bases da educação nacional). Presidência da República. Casa Civil. http://www.planalto.gov.br/ccivil_03/leis/19394.htm 
Brasil. (2006). Lei n 11.274 de 06 de fevereiro de 2006 (Dispõe sobre a duração de 9 [nove] anos para o ensino fundamental, com matrícula obrigatória a partir dos 6 [seis] anos de idade). http://www.planalto.gov.br/ccivil_03/_ato20042006/2006/lei/l11274.htm

Coutinho, A. M. S. (2010). A ação social dos bebês: um estudo etnográfico no contexto da creche. [Tese de Doutorado em Estudos da Criança, Instituto de Educação, Universidade do Minho, Braga]. Repositório UM.

http://repositorium.sdum.uminho.pt/handle/1822/11336

Delgado, A. C. C., \& Nörnberg, M. (2013). Do abrir-se aos pontos de vista e forças do desejo dos bebês e crianças bem pequenas. Linhas Críticas, 19 (38), 147-167. https://doi.org/10.26512/lc.v19i38.4097

Finco, D., Gobbi, M. A., \& Faria, A. L. G. de (orgs.) (2015). Creche e feminismo: desafios atuais para uma educação descolonizadora. Edições Leitura Crítica; Associação de Leitura do Brasil - ALB; Fundação Carlos Chagas.

https://www.fcc.org.br/livros/CRECHE E FEMINISMO Donwload pedro menor.pdf

Finco, D., Silva, A. A.,\& Faria, A. L. G. de (2018). Dossiê: Feminismo em estado de alerta na educação das crianças pequenas em creches e pré-escolas. Revista Zero-a-Seis, 20 (37), 2-10. https://doi.org/10.5007/1980-4512.2018v20n37p2

Gottlieb, A. (2012). Tudo começa na outra vida: a cultura dos recém-nascidos no Oeste da África. Editora Fap-Unifesp.

Guimarães, D. (2008). Relações entre Crianças e Adultos no Berçário de uma Creche Pública na Cidade do Rio de Janeiro: técnicas corporais, responsividade, cuidado. [Tese de doutorado em Educação, Pontifícia Universidade Católica do Rio de Janeiro-PUC-Rio]. Repositório Institucional da Puc-Rio.

https://doi.org/10.17771/PUCRio.acad.12204

Haddad; L. (1991). A creche em busca de identidade: perspectivas e conflitos na construção de um projeto educativo. Edições Loyola.

Ingold, T. (2019). Sobre levar os outros a sério. Em T. Ingold. Antropologia: para que serve? (pp. 7-19) Vozes.

Jobim e Souza, S.,\& Pereira, M. R. R. (1998).Infância, conhecimento e contemporaneidade. Em S. Kramer, \& M. I. F. P. Leite. (Orgs). Infância e produção cultural (pp. 25-42). Papirus.

Kramer, S. (2003). A política do pré-escolar no Brasil. A arte do disfarce (3a edição). Cortez.

Mattos, M. N. S. S. (2018). Bebês e livros: relação, sutileza, reciprocidade e vínculo. [Tese de doutorado, Pontifícia Universidade Católica do Rio de Janeiro]. Repositório Institucional da Puc-Rio. https://www.maxwell.vrac.puc-rio.br/33313/33313.PDF

Moura, S. M. S. R. De, \& Araújo, M. de F. (2004). A Maternidade na História e a História dos Cuidados Maternos. Psicologia Ciência e Profissão, 24 (1), 44-55. https://doi.org/10.1590/S1414-98932004000100006

Mukasonga, S. (2017). A mulher dos pés descalços (Tradução Marília Garcia). Editora Nós. 
Nascimento, A., Salutto, N., \&Barbosa, S. N. F. (2020). Editorial. Revista Interinstitucional Artes de Educar, 6 (2), 439-443. https://doi.org/10.12957/riae.2020.51022

Pino, A. (2005). As marcas do humano. Editora Cortez.

Ploennes, C. (2014, setembro 15). Incluir os bebês é preciso. [Entrevista com Fúlvia Rosemberg]. Revista Educação. http://www.revistaeducacao.com.br/incluir-osbebes-e-preciso/

Priori, M. Del. (2018). Apresentação. Em M. Del Priori (org.). História das Mulheres no Brasil (pp. 7-10). Contexto.

Priori, M. Del. (2020, setembro 02). As Transformações nas relações entre mães e filhos nos séculos XIX e XX [Vídeo]. YouTube.

https://www.youtube.com/watch? v=ZOOgafeEB g

Rezende, C. B. (2015). O parto em contexto: narrativas da gravidez entre gestantes no

Rio de Janeiro. Civitas - Revista de Ciências Sociais, 15 (2), 214-228.

https://doi.org/10.15448/1984-7289.2015.2.18947

Rosemberg, F. (1989). Creche. Cortez

Rosemberg, F. (2015). São Paulo: uma cidade hostil aos bebês. Em A. Artes, \& S.

Unbehaum. Escritos de Fúlvia Rosemberg (pp. 2010-2015). Cortez.

Santos, J. R. dos. (2009). Ovodoação: vivências das doadoras e receptoras de óvulos em um hospital universitário [Dissertação Mestrado, Universidade de São Paulo].

Biblioteca Digital de Teses e Dissertações da USP.

https://teses.usp.br/teses/disponiveis/5/5160/tde-02092009-

165018/publico/JulianaRobertoSantos.pdf

Scavone, L. (2001). Maternidade: transformações na família e nas relações de gênero.

Interseções: Revista de Estudos Interdisciplinares, 5 (8), 47-60.

https://www.scielo.br/pdf/icse/v5n8/04.pdf

Scavone, L. (2004). Dar a vida e cuidar da vida: Feminismo e Ciências Sociais. Editora UNESP.

Técnica Alexander. (s.d.). Técnica Alexander.

http://www.tecnicadealexander.com/tecnica.php

\section{Biografia}

\section{Nazareth Salutto}

Doutora em Educação Brasileira pela Pontifícia Universidade Católica do Rio de Janeiro (2018). Professora Adjunta da Faculdade de Educação da Universidade Federal Fluminense. Coordenadora do Grupo de Pesquisa e Estudo em Educação, Infância, Bebês e Crianças/GERAR.

E-mail: nazarethssalutto@gmail.com

ORCID: https://orcid.org/0000-0001-8043-595X

Licença Creative Commons. Este trabalho está licenciado sob uma Licença Internacional Creative Commons Attribution 4.0 .

Salutto, N. "É preciso incluir os bebês!" Sentidos e apostas no diálogo com mulheres-mães 20 